\title{
FUTURE ORIENTATION AND SOCIALIZATION *
}

\author{
Gisela TROMMSDORFF \\ Technische Hochschule, Aachen, FRG
}

\begin{abstract}
The present paper deals with the question of what kind of relationship may exist between future orientation and socialization. First, the nature of future orientation and related person variables are discussed. It is shown that a functional theory of personality and social behavior is needed in order to specify the relations between these variables. On the basis of such a theory the next question on the development of future orientation may be dealt with more fruitfully. Besides cognitive maturation, social experiences determine which kind of future orientation develops and can be adapted in different social situations. Finally, the question is dealt with to what extent futurc orientation (not only of parents and teachers, but also of the person to be socialized) may influence the process and result of socialization. Some preliminary data indicate the usefulness of an interactionist theory for the study on the relation between socialization and future orientation.
\end{abstract}

\section{Introduction}

Socialization is always future oriented, and future orientation (as a component of the person's time perspective) is an integral part of the socialized personality.

At first sight, future orientation might be considered an important goal for educational activities. Research on future orientation gives the impression that a well-structured and extended future orientation is a characteristic of a well-adapted personality (Wallace 1956) and allows for activities which are highly valued in our culture - such as delay of gratification, planning, problem solving and achievement (cf. Mischel 1974, 1981; Teahan 1958).

However, before prescriptive theories may decide whether future orientation should be an educational goal, a descriptive and functional theory on the complex relations between future orientation and sociali-

* Part of this study has been conducted in the Sonderforschungsbereich 24, Universität Mannheim, and has been supported by a grant from the Deutsche Forschungsgemeinschaft. The author is grateful to Helmut Lamm and Wolfgang Woerner for their valuable comments on the first draft of the manuscript.

Requests for reprints should be sent to the author's address: Institut für Erziehungswissenschaft, Technische Hochschule, Templergraben, D-5100 Aachen, FRG.

Konstanzer Online-Publikations-System (KOPS)

URN: http://nbn-resolving.de/urn:nbn:de:bsz:352-opus-85037

URL: http://kops.ub.uni-konstanz.de/volltexte/2009/8503/ 
zation has to be worked out. The concept of future orientation, its relation to other person and social variables, its functions for human behavior, and its developmental conditions in the process of education and socialization have to be clarified in such a theoretical approach.

These questions will be dealt with in the first part of this paper. The second part will focus on future orientation as an integral part of socialization activities. Specifically, function and development of future orientation, as a part of interpersonal relations between parents (or teachers) and children will be discussed.

\section{Future orientation: Conceptualization, functions, development}

\section{Conceptualization}

The study of time perspective deals with the content, duration, or directionality of the subjective experience of time -.. of past, present and future. Future time orientation is part of time perspective. The different theoretical and methodological approaches to the study of time perspective and future orientation - stemming from psychoanalysis, learning or cognitive theories - have led to different conceptualizations of future orientation and to inconsistent findings.

Kastenbaum (1961), e.g., demonstrated that several logically distinci indicators of temporal perspective all loaded on the same factor which he called "general concern for future events". However, in subsequent studies no systematic relationships between these distinct measures could be demonstrated (Lessing 1968; Ruiz et al. 1967; Plati et al. 1971).

When looking more closely at studies on future orientation and the different measures used (direct and indirect personal and impersonal measures; structured questionnaires, tests, and projective measures) (for reviews see Winnubst 1975; De Volder 1979) it becomes clear that frequently the same label has been used for different aspects of a complex cognitive-motivational system: some studies on future orientation take into consideration only cognitive aspects such as extension and coherence of future orientation (e.g., Wallace 1956); other studies focus on motivational aspects of future orientation measuring subjective needs and the anticipations of need satisfaction in the near or distant future (e.g., Nuttin 1964). 


\section{Components of future orientation}

Cognitive aspects

A rather narrow definition of future orientation restricts itself to the measure of the extension of time perspective into the future, the coherence (cf. Wallace 1956), or the density of anticipations (Kastenbaum 1961). Following Rotter's (1966) distinction between internal and external control, we have recently introduced another aspect of cogniive structuring: the judgment of internal versus external causality (Trommsdorff and Lamm 1975).

These rather different conceptualizations of future orientation may be seen as specific cognitive aspects which are part of a general cognitive schema (cf. Piaget 1946; Kelly 1955). Future orientation as a cognitive schema means the structuring of future events in terms of their temporal sequence and causal order. Such anticipatory cognitive schemata can be more or less extended, differentiated, precise, coherent, and realistic. They can be focused on internal rather than on external causes of future events, and on possible developments of the self or the environment; they are organized and structured according to the thematic content of the respective anticipations. The thematic content can presumably shape the cognitive structures, since it specifies for a given situation the individually relevant goals and motives.

Here, the evaluative, affective and motivational components of future orientation come into play.

\section{Motivational and affective aspects}

The future can be experienced as more optimistic or pessimistic (cf. Knapp and Garbutt 1958; Trommsdorff and Lamm 1975; Beck et al. 1974; Füchsle et al. 1980; Trommsdorff et al. 1982). This affective quality of future orientation presumably influences individual behavior and thus should be studied in addition to the cognitive and temporal structuring of the future. The subjective future does not only comprise cognitive schemata but also goals, hopes, fears, and wishes. These motivational and affective aspects are presumably related to the cognitive structuring in complex ways, depending on the situational context and the thematic content of the anticipations which can activate individually relevant goals and motives.

The motivational approach conceives of future orientation as a central part of all motivated activity (Nuttin 1964). Human motives are 
directed toward goals which may be attained in the near or distant future. Such goals may be to achieve certain ends and to satisfy certain needs and wishes; or they may consist in avoiding certain fears and undesired events. A situation can be motivating if need-satisfaction is expected. These expectations are oriented to the kind of consequences of the activity, the judgment of adequate preconditions for successful activities (e.g., internal or external conditions), and the probability of success in the given situation. Together with such expectations, the value of specific goals should shape future orientation and determine related activities.

This conceptualization (see also Trommsdorff and Lamm 1975; Füchsle et al. 1980) stresses the multi-dimensionality of future orientation and follows Lewin's $(1948,1965)$ approach to time perspective. Especially his discussion on aspirations, hopes, fears, goals, and anticipations as part of future time perspective have influenced theoretical work on personality, decision making, achievement motivation, and social interaction. Modern expectancy value theories (Atkinson 1967; Vroom 1964; Heckhausen 1980) are heavily leaning on Lewin's ideas. and have inspired recent research on future orientation (Raynor 1970 , 1974; Raynor and Entin 1982; Gjesme 1976, 1981).

In the present paper, we will understand future orientation as a multi-dimensional cognitive-motivational construct: cognitive schemata on the subjective future may be differentiated according to their temporal and causal structure and underlying subjective judgments of future events as more or less probable; the motivational and affective quality of the subjective future may be differentiated according to the affective quality of the future (as more or less positive or threatening) and its specific thematic content (goals).

The problem for our further discussion will be that we have to deal with studies which are based on different operationalizations of future orientation, most of them only taking into account one single aspect of this complex phenomenon.

\section{Future orientation and its relation to other person variables}

In contrast to the trait psychological approach, conceiving of future orientation as a stable personality characteristic, Lewin has always assumed mutual interdependencies between the person and his/her environment. However, situational variables such as affect or mood-inducing states have only recently been taken into account as influencing 
time perspective (Kastenbaum 1965; Gorman and Weissman 1977).

Future orientation and its relation to other person variables might be affected by situational conditions - which in turn may be changed on account of future oriented behavior. We will try to apply this central idea from Lewin's interactionist approach to our discussion of future orientation and socialization.

The nature of systematic relations between future orientation and other person variables is very unclear. Research on such correlations was often guided by clinical interest, following the general assumption that an extended future orientation guarantees a well-adapted and psychologically healthy personality. In these studies, future orientation has been conceptualized in different ways and was related to such variables as anxiety (Krauss et al. 1967), self-concept (Platt and Taylor 1966), dogmatism (Zurcher et al. 1967), achievement motivation (Gjesme 1979; De Volder 1979), internal control (Platt and Eisenman 1968), or schizophrenia (Wallace 1956). Furthermore, future orientation has been studied in relation to observable behavior such as achievement (Raynor 1974; Raynor and Entin 1982; Gjesme 1976), delay of gratification (Gjesme 1979; Trommsdorff et al. 1978a; Trommsdorff et al. 1979a), problem solving (Dörner 1974), or consuming behavior (Bouwen 1977). In some of these studies, such relations are significant in the expected direction, in other studies, relations between future orientation and behavior are mediated by other variables, or do not emerge at all.

Some of the inconsistencies between these studies can be explained if we take into account that interrelations between different measures of future orientation can be mediated by third factors: For example, they can be positive for emotionally disturbed persons and negative for normals (Lessing 1968). These and similar findings (e.g., Spivack and Levine 1963) demonstrate again that future orientation is a multi-dimensional construct consisting of variables which are interrelated, and which are differentially related to other personality variables in different populations.

If only one aspect of future orientation is related to other person variables, no clear pattern of results may be expected. This can very well be demonstrated for studies on extension of future orientation (cf. Lessing 1972; Klineberg 1967; Trommsdorff et al. 1982).

Extension can have a psychologically different function in the context of other aspects of future orientation, other personality variables, and situational conditions. An extended future orientation as such does 
not necessarily indicate a well-adapted personality. Older persons have a shorter extension of future time perspective than adolescents, since their life expectancy is shorter (Nuttin and Grommen 1975; Trommsdorff 1982). In an early stage of development, normal adolescents have a shorter but more realistic future time perspective than maladjusted adolescents, who are more influenced by wishful-thinking tendencies (Klineberg 1967).

This result indicates that in case of cognitive difficulties to envision the future it is more appropriate to direct one's thinking and behavior to events and goals in the near future. Here, a less elaborated ability for abstraction or cognitive development is required. Bandura and Schunk's (1981) finding that children with learning difficulties are more successful if they set themselves learning goals in the ncar future supports this interpretation.

Certain cognitive and situational factors can combine in a way that makes it more useful for the person to develop a rather less extended future orientation. A less extended and less structured future time perspective of delinquents as compared to nondelinquents (e.g., Barndt and Johnson 1955; Stein et al. 1968; Black and Gregson 1973) is usually interpreted as a precondition for delinquency, or an effect of delinquents' inability to control their impulses and to delay gratifications. However, no clear correlations between delay of gratification and extension of future time perspective could be demonstrated by Lösel (1975) for self-reported delinquency and by Trommsdorff et al. (1979a) for fcmalc delinquents.

A low extension of future orientation might just as well be a kind of adaptation to situational conditions. Low extension could result as a consequence of labeling processes, or of institutionalization as delinquent, as data from Trommsdorff and Lamm (1980) indicate. When taking into account the thematic content of future orientation, we were able to demonstrate that delinquents have a rather realistic view of their future: they expect their hopes to be fulfilled in the distant future and their fears in the near future (Trommsdorff et al. 1979a). Contrary to the often assumed wishful thinking and optimistic future orientation of delinquents (Landau 1975, 1976) we were also able to show that delinquents realistically structure their future more in terms of fears than hopes (Trommsdorff and Lamm 1980). These findings support the hypothesis that a less extended future orientation of delinquents may be quite functional for this group since most problems have to be coped 
with in the near future; and realistically the distant future cannot be expected to be positive.

In the same line, it seems much too simple to assume a linear correlation between aggression and the extension of future orientation. The time span for the future could cover all kinds of near or distant goals which may be more or less aggressive or instrumental for aggressive acts. The relation between future orientation, delinquency, and aggression is more complex (cf. Burger and Trommsdorff 1982) and should be studied in respect to other cognitive-motivational variables such as attributions, belief in equity, or anger-arousing affects (cf. Kornadt 1982). If extension as an aspect of future orientation is related to other person variables, it should first be clarified whether indicators of extension merely measure fantasies or rather specific anticipations involving strategic steps to attain a goal (cf. Wohlford and Herrera, 1970). Accordingly, an extended future orientation may be an undesirable educational result.

Such functional theoretical reasoning allows one to specify relations between future orientation or certain of its aspects, and other person variables, or individual behavior, such as delay capacity, planning, problem solving or achievement which may be desired educational goals.

In fact, Raynor $(1969,1974)$, De Volder and Lens (1982), and Gjesme $(1979,1981)$ were able to support several theoretically derived hypotheses on the relationship between future orientation and achievement. These authors follow the expectancy-value-based version of achievement motivation theory and its differentiation by Atkinson and Raynor (1974) and Heckhausen (1980). Raynor (1974; Raynor and Entin 1982) demonstrated the usefulness of taking into account (1) the goal's perceived physical distance in time as the situational factor; and (2) the individual's future time orientation. These two factors are assumed to interact and determine the individual's perceived goal distance in time (which must not be equivalent to the expectancy of reaching the goal); this, in turn, determines the effects of achievement motives on present activities (Gjesme 1981).

In the experimental tests of his theory, Gjesme (1976) was clearly able to demonstrate that for anxious persons who anticipated the occurrence of fear-arousing events (achievements) in the near (as compared to the distant) future, a performance decrement resulted. Presumably, negative affects associated with the future event inhibit taskrelevant behavior. 
Gjesme (1981) conceives of future time orientation as a quasi-stable personality variable which is not differentiated with respect to the thematic content of the future; however, his results may be interpreted as the effect of emotions and affects associated with certain contents of anticipated future events. Depending on the hopes of fears associated with such anticipations, either approach or avoidance tendencies should result, determining the probability of successfully reaching the goal.

While Gjesme focuses on the psychological distance and perceived instrumentality as interacting variables of future orientation, De Volder and Lens (1982) conceive of future orientation as (a) the valence of distant goals, and (b) the anticipation of long-term consequences of actual behavior (instrumentality). This evaluative (dynamic) and cognitive aspect of future orientation is related to different kinds of behavior (thematic content of goal objects). The authors show that highly achieving students attach higher valence to distant goals and perceive studying hard as more instrumental for reaching goals in the far future.

These theoretically well-founded studies on the relationship between future orientation and achievement should encourage further research on the relation between future orientation and other educational goals such as delay, planning, or problem solving (Trommsdorff et al. 1978b, 1979a).

In our own work, we also follow the expectancy-value-approach, including (besides temporal and cognitive structuring and affective meaning of the future) another aspect of instrumentality: the anticipated causality of future events (Trommsdorff et al. 1982). If one feels responsible for one's future outcomes, one is presumably more motivated to invest activities for preventing undesired outcomes or attaining desired future events. Preliminary (unpublished) data from our recent study on the impact of future orientation on decision making show that beside the structuring of anticipations, affects associated with the future and control beliefs predict the extent of planning activities (coping) for mothers who face a problematic empty-nest period in the near future.

These studies show that an extended or optimistic future orientation per se cannot be an adequate goal in socialization or education. Before discussing what aspects of future orientation should be goals for personality development, the relations between the cognitive, motivational, and affective components of future orientation should first be clarified on the basis of a functional theory of personality and social behavior. 


\section{Development of future orientation}

Depending on a rather mechanistic or active view, human development can be studied as a process determined by rather exogenous or rather endogenous factors. Psychoanalytic and cognitive approaches tend to focus on the endogenous processes while the behaviorist approach stresses exogenous factors as determinants of human development.

\section{Endogenous processes}

According to the psychoanalytic approach (Freud 1954) the child gradually develops its ego and superego through systematic frustrating experiences. These reality-oriented structures include, among other abilities, the capacity to plan and to delay gratification.

The cognitive developmental approach has made important contributions to understanding the development of the subjective experience of time. In Piaget's $(1946,1966,1970)$ theory, cognitive development proceeds from simple reflexive behavior and concrete cognitive representations, to more complex, formal, and abstract conceptualizations of reality. Concepts of time develop in a way similar to concepts of space, volume, or matter; e.g., the child derives concepts of time from relationships among more simple concepts such as work and power (Piaget 1966). Accordingly, one has to assume that formal operational intelligence enables the child to anticipate consequences and to think in terms of future possibilities instead of simple prolongation of actions or operations. Following this assumption, several studies were able to show that children and adolescents learn to structure their future more complexly: they increase the length of their future orientation (Klineberg 1967; Shannon 1975), become more realistic (Klineberg 1967; Trommsdorff et al. 1978b), and anticipate future events less as controlled by oneself, while increasingly taking into consideration external factors (Trommsdorff et al. 1978a).

However, besides pure cognitive maturation, social experiences seem to influence the development of future orientation considerably.

\section{Impact of social factors}

Considering the question in how far social conditions can determine the development of future orientation, it may be useful to focus on psychologically relevant variables such as the degree of restrictiveness in social conditions: depending on the extent of realistic possibilities for 
economic success or other kinds of goal attainment - as represented by the given social circumstances - the future time perspective should be more oriented to available rewards either in the immediate or in the more distant future. In the first case, future orientation needs less complex structuring since fewer instrumental activities are necessary to reach less distant goals; extensive cognitive structuring should be adequate if more distant goals are to be attained.

The results of Klineberg (1967) on adjusted as compared to maladjusted children from lower social class support these hypotheses. Welladjusted pre-adolescent children (between the ages of 10 and 12) had a less extended future time perspective than maladjusted children; the latter held wishful fantasies for the distant future. In middle-adolescence (between 14 and 16 years of age), the future orientation of the normal children as compared to the maladjusted group was more expanded, including more realistic anticipations.

This study also shows that, under normal conditions of cognitive development, older children (between 14 and 16 years) are able to anticipate future developments and extend their future time perspective realistically. Unsuccessful persons fail to develop an extended future orientation since - from a realistic point of view -- the future will bring them undesired developments.

Klineberg's (1967) study supports Piaget's cognitive theory on the development of time perspective; furthermore, it shows very clearly that besides by endogenous factors, such as cognitive maturation, the development of future orientation is influenced by situational factors such as social and economic conditions.

Results on future orientation of socially deprived minority groups can be interpreted in the same line. A more extended future orientation in a socially and economically deprived group of Indian Americans is associated with maladaptive social behavior, while a shorter time perspective in this group is related to adaptive behavior (cf. Graves 1972, cited in Shannon 1975).

Thus a future orientation which primarily focuses on the near future and lacks complex structuring can be well adaptive for socially disadvantaged and economically deprived groups.

For socially deprived groups it may be more adaptive to avoid anticipations of the distant future since, realistically, they may only have uncertain or pessimistic expectations. In his comparative study on different cultural groups in the USA, Shannon (1975) supported the 
hypothesis that future orientation may be an effect of social conditions mediated by realistic appraisal of the present and future social situation. Anglo-Americans develop a more extended future orientation with growing age (10-12 and 14-17 year-old groups). This result would be predicted by cognitive theories (Piaget 1966). However, for Indian and Mexican Americans such an increase in extension does not occur. Presumably, adolescents from these minority groups find out about their future difficulties to attain the goals and norms of the majority group.

There is some evidence of a shorter future time perspective in lower-class children (extension measured as the length of future time perspective in a story completion test: LeShan 1952; or as the frequency of using the word "tomorrow": Brock and Del Giudice 1963). However, Judson and Tuttle (1966) did not find differences in extension of future orientation, but more delay of gratification in middle-class as compared to lower-class children.

These inconsistent results are partly due to crude and different indicators chosen for social class and future orientation. For example, extension of future orientation correlates with the length of stories in the completion test - which in turn may depend on the greater verbal fluency of middle-class children (cf. Greene and Roberts, 1961); and a global categorization of social conditions according to prestige, income, or occupation, does not allow to specify the relevant psychological conditions for the development of future orientation. Such relevant conditions may, for example, be the degree of educational status.

Impact of educational status. According to cognitive theories, the level of abstract thinking is a precondition for the capacity to structure the future in a differentiated way. Furthermore, educational level may allow to conceive of one's future as internally controlled and rather positive, if higher achievement and higher educational status lead to higher income and more interesting and satisfying positions. Also, the educational and social status of the parents determine not only their own future orientation but also their socialization goals and their behavior toward their children. Own experience in responsible activities and long-term planning may guide their socialization practices which in turn influence the future orientation of their children. Direct educational training, socialization experiences, and experiences in certain social positions may induce the learning of abstract, realistic thinking, 
personal responsibility, and long-range planning; this may shape the cognitive structure of future orientation accordingly, including its affec-. tive and motivational aspects.

In a longitudinal study, we demonstrated the effect of cognitive and social learning on future orientation (Füchsle and Trommsdorff 1980). At the beginning of school, first-grade children anticipated fewer events for the coming half-year than one year later, and they evaluated the future less positively than younger children. This result supports Piaget's assumption that time perspective develops on account of endogenous processes. However, in this study, the effect of education was also significant: while lower-class as compared to middle-class children evaluated their future more optimistically when entering school, this optimism decreased after the first year of school, while it increased for middle-class children. Furthermore, middle-class children increasingly preferred to delay gratifications. The fact that no age-specific differences for delay occurred does support the notion that future-oriented behavior is determined by cognitive abilities and social motives. Such abilities and motives are obviously better learned in a middle-class environment.

It seems that the school does not compensate for possible socialization defects but rather contributes to increasing differences in socialization and resulting effects on future orientation. Furthermore, it appears that lower-class chiliren lose while middle-class children gain from the first year in school with respect to optimism and delay of gratification. However, our study did not explore which specific factors in family or school might have contributed to such discriminating effects.

In other studies we compared people with different educational level with respect to their future orientation (only those persons were included whose parents both had the same educational status as the respective child). Most of the hypotheses stated above were supported for adults (Schmidt et al. 1978) and for adolescents (Lamm et al. 1976); however, the strength of confirmation varied depending upon the thematic content of the future area. Adolescents with lower education (grammar school) who are facing departure from school and looking for a job have a much more differentiated future orientation for the domain of work than Gymnasium students. Furthermore, their future orientation is less extended in most domains of life than for Gymnasium students, who structure the public future more extensively. While a 
similar difference in extension was found between adults with low versus high level of education, there were no differences among the adults with respect to differentiation.

Grammar school students and adults with grammar school education believed less in their ability to expert personal influence on future events (particularly in the public sphere) than did their more highlyeducated counterparts. The education variable also had an impact on optimism/pessimism in the adult population: adults with a higher level of education judged the distant future more optimistically than those with a grammar school education.

The kind of education people receive influences a broad range of individual experiences and thus, too, the structure of their future orientation. Similarities in future orientation between adults and adolescents with the same educational background suggest that the difference in experiences induced during the years in school are subsequently reinforced by occupation. However, the resulting differences between educational levels are not only of a cognitive and intellectual nature. The motivational character of future orientation is illustrated by our result on differences in optimism among adults and, furthermore, by the fact that the occupational area is less differentiated by highly as compared to less educated adolescents. In the same line, the data of Bouffard (1981) support the interpretation that schooling is no necessary condition for an extended future orientation.

Impact of social roles. The effect of social roles, such as occupation, as another socialization experience to influence one's orientation has been demonstrated in a longitudinal study by Trommsdorff et al. (1979b). We compared adolescents of different educational levels who went to school at the time of the first measurement and who either worked or still went to school at the time of the second measurement. Adolescents with lower educational level (grammar school) who had a more differentiated future orientation than Gymnasium students at the first measurement, with respect to the occupational domain, structured their future in this domain even more precisely, and they increased their belief in internal control of their future after having left school and having worked for about nine months.

Obviously, social roles exert a strong influence on future orientation - presumably because of their impact on individual experiences. New roles and related experiences coming up at different stages of our life 
do not necessarily change future orientation in all of its aspects. certain characteristics of future orientation which stem from some basic cognitive abilities (related to educational level) or social motives (related, e.g., to gender) may remain rather stable across different situationa! influences and through one's lifetime as our studies on future orientation of adolescents (Lamm et al. 1976) and adults (Schmidt et al. 1978) have shown (Trommsdorff et al. 1982).

The findings of the previous studies support the notion that social roles are socialization experiences which influence the content and structure of future orientation. According to traditional sex role socialization, females are more likely than males to be restricted in their experiences to the family domain (Hoffman 1977). This may be less pronounced if females enjoy higher educational opportunities (Lehr 1972). Consequently, the future orientation of females and males especially for lower educational levels ... should differ in respect to its cognitive structure, thematic content, and affective quality.

These hypotheses were partly supported by our own studies (Lamm et al., 1976; Trommsdorff et al., 1980, 1982). Males listed a greater number of hopes and fears in the occupational domain than females, while females structured their future more intensively in the family domain. Only for grammar school but not for the Gymnasium students, the future orientation of females as compared to males was less extended in the occupational domain (Lamm et al. 1976). In another study with Gymnasium students between 11 and 15 years of age, females also structured their future in respect to the family domain more differentiatedly and more extendedly than males; they were also more pessimistic than males with regard to their occupational future (Trommsdorff et al. 1978a).

Females with different educational levels generally showed a more differentiated future orientation than males - as far as the perceived instrumentality of future activities to achieve one's goals is concerned in feared negative events in the family domain and positive events in the occupational domain (Trommsdorff et al. 1980).

Sex-specific differences in the cognitive structure of future orientation obviously depend on the fears or hopes associated with the future domains. When hopes are difficult to realize and fears difficult to avoid, more instrumental activities are necessary. Since hopes for the occupational domain are much harder to achieve for females, they have to look much more intensively for adequate instrumental activities to 
achieve their goals. This is even more necessary if future events are expected to depend rather on external conditions than on oneself - a finding which consistently occurs in our studies on females' as compared to males' future orientation.

These findings demonstrate that socialization experiences of adolescents influence their future orientation in terms of their sex-role. With respect to their occupational future, female adolescents are rather pessimistic and unsure, expecting more difficulties than males.

Independent of age, females structure their future in the family domain in a more differentiated and positive way. Only in adulthood do gender-specific differences in respect to the occupational future change. Adult working women do not structure their occupational future much differently than men, but they still structure their private future more complexly and with a longer extension than men (Schmidt et al. 1978).

Impact of perceived parental behavior. Until now we have discussed the effects of general socialization experiences such as education and social roles on the development of future orientation. In the following, we will focus on some more specific principles of learning, which are more or less consciously integrated in socialization and education, and discuss its possible effects on future orientation.

A general assumption in cognitive social learning theories is that parents who give positive reinforcements to their children and who are consistent in their socialization practices induce in their children a general expectancy of a positive world, trust in others, belief in own abilities, and general optimism (Davis and Phares 1969; MacDonald 1971; Rotter 1966; Mischel 1974). Accordingly, one can assume that children who perceive their parents as loving and supporting should develop a trusting and positive attitude towards the future, believe more in their future success as being a result of own activities, and be more inclined to invest for achievement of future goals than less supported children (cf. Stapf et al. 1972).

In our study on the relation between perceived parental support and future orientation of 11,13 , and 15 year-old children we were generally able to support these hypotheses (Trommsdorff et al. 1978b). Children who perceived little support were less optimistic about their future and less hopeful than children who perceived their parents as highly supporting. 
Children with low support also believed less in their ability to influence their personal future; their future orientation was less structured and extended with regard to the economic and occupational domains.

These results clearly show that perceived parental support influences the structure and affective quality of children's future orientation.

\section{Summary}

Several studies have demonstrated that future orientation develops under the influence of both cognitive maturation and social experiences. Such experiences may shape future orientation as a means to adapt to social givens and possibilities. The impact of socialization can be traced by measuring the cognitive, affective, and motivational aspects of future orientation. Changes in future orientation obviously can occur as a life-long process, though they remain stable in some aspects.

The impact of education on future orientation can be differentiated according to purely cognitive aspects such as higher levels of abstraction, or principles of causality, but also with respect to the affective and motivational aspects of learning to be responsible for certain (desired or undesired) outcomes, to trust and to believe in general positive outcomes, and to differentiate between different thematic aspects of the future which are more or less rclevant for one's goals and positive for oneself.

However, our present knowledge does not yet allow to specify which socialization practices and educational programs shape the person's development in a desired way (Klauer 1982) - or influence the development of future orientation in its different aspects.

\section{Role and effect of future orientation in the process of socialization}

Some of the social influences we have considered so far stem from direct experiences with the agents of socialization. Since socialization and education itself are based on predominantly future-oriented activities, it may well be assumed that parents and teachers influence the process of socialization and the future orientation of the child on account of their own future orientation.

Parents and teachers follow subjective values and goals concerning the desired and undesired development of the child; they structure the 
future in a certain way, and they organize their socialization and educational goals and behavior according to their own hopes, fears and wishes for the future. Their socialization behavior is based on more or less well-structured and extended future-related cognitive schemata, and on more or less positive future-related evaluations and affects. Future orientation of parents and teachers presumably is directed, among other concerns, at certain anticipations and goals related to the future development of their children and students. At present, we know too little about the future orientation of agents of socialization, and what its effect on the person to be socialized may be.

In a recent study, we tried to get more information about the way mothers anticipate and evaluate the future of their children. We compared the mothers' future orientation concerning their children with their children's future orientation concerning their own future, and we analyzed the similarities and discrepancies between both.

We questioned 48 mothers and their 15-17 year-old sons and daughters separately. The adolescents ( 24 boys and 24 girls) answered the Future-Orientation-Questionnaire (Trommsdorff and Lamm 1976), and each mother indicated for each item of this questionnaire how she believed the future of her son or daughter would be. Thus, we were able to compare mothers' and adolescents' responses to the same item, measuring extension and optimism of future orientation.

Considerable differences in the anticipation and evaluation of the future occurred between mothers and their children: mothers believed that future events (hopes and fears for their children) would occur at an earlier time in the future than was expected by adolescents $(F=$ $21.67, p<0.001)$. Furthermore, they were more optimistic than adolescents (for the near future in 5 years: $F=5,49, p<0.05$; for the distant future in 20 years: $F=4.55, p<0.05$ ). Here, interesting interaction effects occurred: mothers were more optimistic for the near and far future of their sons than for their daughters' future ( $F=4.81$ and 6.88 ; $p<0.05$ ) (see fig. 1).

In respect to evaluating the future, mothers agreed more with their daughters than with their sons, but we do not know whether this depends on the mothers' lower aspirations for and/or their closer relation with daughters and related similarity in goals and expectations.

This study raises several questions: What are the possible effects of the kind of relationship between parents (teachers) and adolescents in respect to their future orientation and personality development? Is a 


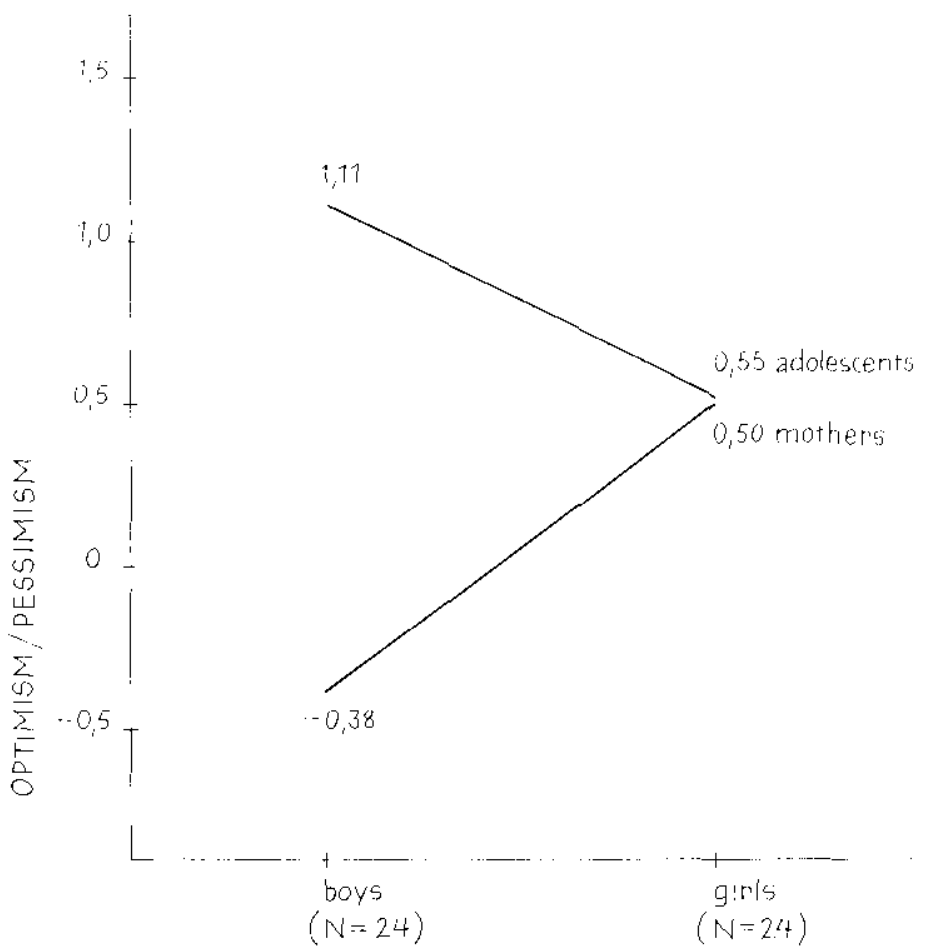

Fig. 1. Optimism of mothers and their children. The present and future (in 5 years) were evaluated in respect to subjective well-being on an 11-point scale $(0=$ worst $\ldots, 10=$ best). Optimism is the difference between present minus future (sum of 5 items) (negative value: optimism, and positive value: pessinism).

more intimate, positive interpersonal relation a precondition or a result of similarity in future orientation? What degree of optimism and extension in future orientation is necessary on the part of the parent and on the part of the child to stimulate successful personality development of the child?

From studies on socialization effects on achievement motivation we know that realistic expectations (not demanding too little or too much from the child) improve the development of achievement motivation (Heckhausen 1980). However, it is difficult to say whether great discrepancies between mothers' and children's future orientation are an indicator of unrealistic (wishful or pessimistic) thinking by either part. Nevertheless, mothers' expectations should influence the way their children anticipate and evaluate their future. 
Studies on the effect of teachers' expectations on students' achievement-related expectations and behavior lead one to assume a certain tendency for self-fulfilling prophecy (Rosenthal 1974). Teachers' beliefs in their students' success seem to motivate teachers to communicate more with such students, to pay more attention to what they are saying, and/or to encourage them more verbally and nonverbally (Good and Brophy 1977). This behavior positively reinforces and motivates the student to try hard and be successful. The positive experience of success in school in turn contributes to the development of an optimistic, self-assured future orientation in these students. Accordingly, one may hypothesize that optimistic expectations of teachers concerning students' success is related to an optimistic future orientation of these students.

How does the teacher develop such expectations? Presumably, the naive personality theory of the teacher and his/her perception of the student's behavior influences the teacher's expectations of his/her student's success. The student's behavior in turn can be determined by his/her teacher's expectations and the student's individual future time perspective.

Empirical data are in line with the assumed interdependencies. In a recent study, we have asked the teachers of 129 female students to indicate for each student the probability of her success in school and for the time after leaving school (7-point scale). The scale consisted of 15 items (e.g. item 1: "Is this student successful in the subject you are teaching?"; item 10: "Do you believe that this student will generally be successful in achievements at school?"). We asked only teachers who had spent a rather large amount of time in the class of the tested students and thus knew the students quite well. The students answered the Future-Orientation-Questionnaire of Trommsdorff and Lamm (1976). They first indicated their hopes and fears for the future, then they rated each of their hopes and fears according to the following questions: (a) How probable is the occurrence of the future event $(0=$ not at all probable, $\ldots, 10=$ certain $)$; (b) to what extent will the occurrence of the future event depend rather on external conditions (other persons, luck, fate) or rather on internal conditions (your own personal abilities and activities) (continuous scale: 1-depends rather on external ... 7 internal conditions).

Analyses of variance show that students with high as compared to those with low expected success (as rated by the teacher) were signifi- 
Table 1

Students' optimism (probability estimates) and control expectation concerning hopes for the personal future.

\begin{tabular}{lllll}
\hline & \multicolumn{2}{l}{$\begin{array}{l}\text { Teacher rating of } \\
\text { expected success }\end{array}$} & F-value & $p$ \\
\cline { 2 - 4 } & High & Low & & \\
\hline Optimism " & 5.44 & 4.33 & 6.46 & $<0.01$ \\
Control expectation $^{\circ}$ & 3.75 & 3.29 & 5.32 & $<0.02$ \\
\hline
\end{tabular}

a Probability estimates $(0=$ not at all probable, $\ldots, 10=$ certain $)$.

${ }^{\mathrm{b}}$ Ratings of internal or internal control $(1=$ depends rather on external circumstances.... $7=$ depends rather on own personal activities/abilities).

cantly more optimistic (probability of occurrence of hopes) ( $F=6.46$, $d f=79, p<0.01)$ and believed more in internal control of their hopes $(F=5.32, d f=79, p<0.02$ ) (see table 1 ).

Obviously, teachers' expectations of future success are strongly related to students' own future orientation: students who are expected to be successful are more optimistic and believe more in their ability to control their personal future; furthermore, they structure their future in a more differentiated way than students who are expected to be less successful.

However, these data do not allow to conceive of teachers' or students' luture orientation as purely "independent" variables. It can rather be assumed that teachers' and students' future orientation is shaped in the process of interaction which in turn may be determined (besides by cognitive schemata, patterns of interpersonal perception and evaluation, quality of interpersonal relation and behavior) by the future orientation of the interacting persons. In future research, the general and teaching-specific future orientation of teachers and students should be taken into account as possible factors influencing the process of education, the achievement behavior and the future orientation of students.

One recent study on the effect of teachers' future orientation on their teaching style in school may be a first step in that direction. Rheinberg (1980) was able to demonstrate that a short extension of future time perspective occurs for teachers who prefer the reference to social as compared to individual norms when evaluating pupils' achievements. Furthermore, several studies show that the preference for social norms 
(comparison with the average achievement of the whole group) as compared to individual norms (comparison with own achievements) increases the achievement motivation of less successful pupils and lowers their level of achievement anxiety (Rheinberg 1980; Trudewind and Kohne 1982). A less extended future orientation of the teacher is presumably a correlate of such teaching style which gives anxious pupils a better chance for achievement in school.

Further studies on the effect of teachers' or parents' subjective future orientation on the socialization processes and results are needed. Existing evidence on the self-fulfilling effects of teachers' expectations may guide the formulation of hypotheses for future research. Longitudinal studies may answer these and other questions and show by which processes and to what extent the future orientation of parents or teachers and of adolescents influence each other, and which cognitivemotivational and behavioral factors, resulting from interpersonal interactions during socialization, may mediate such inter- and intra-personal processes.

\section{Conclusion}

What kind of future orientation should be a goal for socialization and education? The answer is not so simple from an interactionist and motivation-theory point of view. The value of future orientation and its components depends to a large degree on cultural and social conditions which determine what kind of behavior is appropriate, and how these conditions are subjectively interpreted by the person.

We have seen that it is too simple to assume that an extended future orientation ensures the development of a well-adapted personality, i.e., a person who possesses the ability to control his/her impulses, to delay gratifications, to set realistic goals, to be successful in achievement situations, to plan realistically, and to solve problems efficiently or to be capable of higher learning. Some aspects of future orientation are related to these variables, but the relationships between future orientation and these variables are much more complicated than originally assumed.

Our own studies on German adolescents, or Bouffard's (1981) on African adolescents, have shown that educational status and cognitive training are not preconditions of an extended and well-structured future 
orientation. The acquisition of cognitive skills may not necessarily lead to a more extended future orientation. General cognitive training and basic academic skills are essential for coping and problem solving but they are not necessarily a prerequisite for the cognitive structure of future orientation, since other factors such as motivations and social experiences are also relevant.

In contrast to the assumption underlying much research on future orientation that a lack of future orientation indicates failure, the studies presented here should warn against blindly adopting an ideal of an extended future orientation which may induce maladaptive behavior for certain persons and social groups.

Better knowledge of the cognitive structure, the motivational and affective quality of future orientation, its determinants, and its influence on individual and social behavior under the respective social conditions is necessary before any decision may be made on which kind of future orientation to choose as socialization goal.

It has been shown here that future orientation develops on account of cognitive development and subjective experiences in the course of life-long socialization.

Socialization is a life-long process by which future orientation (and related person variables) are developed and shaped; but in this process. future orientation is a necessary vehicle -- a means for higher learning, a variable which guides the socialization practices and the behavior of the person to be socialized.

Socialization and future orientation are interrelated in several ways: socialization and educational activities are governed by subjective future orientation which in turn influence the future orientation of the person to be socialized. However, the complicated process of such interdependencies still has to be clarified theoretically and empirically in longitudinal studies.

\section{References}

Atkinson, J.W.. 1967. Motivational determinants of risk-taking hehavior. Psychological Revicw 64, $359-372$.

Atkinson, J.W. and J.O. Raynor (eds.), 1974. Motivation and achievement. Washington, DC: Winston.

Bandura, A. and D.H. Schunk, 1981. Cultivating competence, self-efficacy, and intrinsic interest through proximal self-motivation. Journal of Personality and Social Psychology 41, 586-598. 
Barndt, R.J. and D.M. Johnson, 1955. Time orientation in delinquents. Journal of Abnormal and Social Psychology 51, 343-345.

Beck, A.T., A. Weissman, D. Lester and L. Trexler, 1974. The measurement of pessimism: the hopelessness scale. Journal of Consulting \& Clinical Psychology 42, 861-865.

Black, W.A.M. and R.A. Gregson, 1973. Time perspective, purpose in life, extraversion and neuroticism in New Zealand prisoners. British Journal of Social and Clinical Psychology 12, $50-60$.

Bouffard. L., 1981. La perspective future chez les Africains. Unpublished manuscript, Collège de Sherbrooke, Québec.

Bouwen, R., 1977. Anticipation and realization: attitudes and buying plans in the future time orientation of consumer behavior. Psychologica Belgica 12, 113-134.

Brock, T. and C. Del Giudice, 1963. Stealing and temporal orientation. Journal of Abnormal and Social Psychology 1, 91...94.

Burger, C. and G. Trommsdorff, 1982. Bedeutung der Zukunftsorientierung für Aggressivität. Unpublished data. Sonderforschungsbereich 24, Universität Manriheim.

Davis, W.L. and E.J. Phares, 1969. Parental antecedents of internal-external control of reinforcement. Psychological Reports 24, 427-436.

De Volder, M., 1979. Time orientation: a review. Psychologica Belgica 19, 61.79.

De Volder, M. and W. Lens, 1982. Academic achievement and future time perspective as a cognitive-motivational concept. Journal of Personality and Social Psychology 42, 566-571.

Dörner, D., 1974. Die kognitive Organisation beim Problemlösen. Bern: Huber.

Freud, S., 1954. Abriss der Psychoanalyse. Frankfurt: Fischer.

Füchsle, T. and G. Trommsdorff, 1980. Eine Jüngsschnittstudie zur Entwicklung von Zukunftsorienticrung und Aufschubverhalten bei Unter- und Mittelschichtkindern. Zeitschrift für Entwicklungspsychologie und Pädagogische Psychologie 12, 291-300.

Füchsle, T., G. Trommsdorff and C. Burger, 1980. Entwicklung eines Messinstrumentes zur Erfassung der Zukunftsorientierung. Diagnostica 26, 186-197.

Gjesme, T., 1976. Future-time gradients for performance in test anxious individuals. Perceptual and Motor Skills 42, 235-242.

Gjesme, T., 1979. Future time orientation as a function of achicvement motives, ability, delay of gratification, and sex. Journal of Psychology 101, 173-188.

Gjesme, $T_{.,}$1981. Is there any future in achievement motivation? Motivation and Emotion 5 , I1 $15 \cdot-138$.

Good, T. and J. Brophy, 1977. Educational psychology. A realistic approach. New York: Holt, Rinehart \& Winston.

Gorman, B.S. and A.E. Wessman, 1977. 'Images, values, and concepts of time in psychological research'. In: B.S. Gorman and A.E. Wessnan (eds.), The personal experience of time. New York/London: Plenum Press.

Graves, T.D., 1972. Urban Indian personality and the "culture of poverty". Unpublished manuscript, University of California, Los Angeles.

Greene, J.E. and A.H. Roberts, 1961. Time orientation and social class: a correction. Journal of Abnormal and Social Psychology 62, 141.

Heckhausen, H., 1980. Motivation and soziales Handeln. Heidelberg/New York: Springer.

Hoffman, L.W., 1977. Changes in family roles, socialization, and sex differences. American Psychologist 32, 644-656.

Judson, A.J. and C.E. Tuttle, 1966. Time perspective and social class. Perceptual and Motor Skills $23,1074$.

Kastenbaum, R., 1961. The dimension of future time perspective: an experimental analysis. Joumal of Genctic Psychology 45, 203-218.

Kastenbaum, R., 1965. The direction of time perspective: I. The influence of affective set. Journal of General Psychology 73, 189-201. 
Kelly. G.A., 1955. The psychology of personal constructs. New York: Norton.

Klauer, K.J., 1982. 'Über die Notwendigkeit, Möglichkeiten und Grenzen empirisch-pädagogischer Lehrzielforschung'. In: E. König and P. Zedler (eds.). Frziehungswissenschaftliche Forschung: Positionen, Perspektiven, Probleme. Paderborn: F. Schöningh: München: W. Fink. pp. 125149.

Klineberg, S.L., 1967. Changes in outlook on the future between childhood and adolescence. Journal of Personality and Social Psychology 7, 185-193.

Knapp, R.H. and J.T. Garbutt, 1958. Time imagery and the achievement motive. Iournal of Personality 26, 426-434.

Kornadı, H.-J., 1982. Aggressionsmotiv und Aggressionshemmung. Band I. Empirische und theoretische Untersuchungen zu einer Motivationstheorie der Aggression und zur Konstruktvalidierung eines Aggressions-TAT. Bern/Stuttgart/Wien: Huber.

Krauss, H.H., G.J. Mozdzierz, R.A. Ruiz and J. Button. 1967. Anxiety and temporal perspective among normals in a stressful life situation. Psychological Reports 21, 721-724.

Lamm. H., R.W. Schmidt and G. Trommsdorff, 1976. Sex and social class as determinants of future orientation (timé perspective) in adolescents. Jourual of Personality and Social Psychology 34, 317-326.

Landau. S.F., 1975. Future time perspective of delingulents and non-definquents: the effect of institutionalization. Criminal Justice and Behavior 2, 22-36.

Landaw, S.F., 1976. Delinquency, institutionalization, and time orientation. Journal of Consulting and Clinical Psychology 4, 745 - 759.

Lehr, U., 1972. Das Problem der Sozialisation geschlechtstypischer Verhaltensweisen. Handbuch der Psychologie, Bd. VIl: Sozialpsychologie, 2. Halbband. Göttingen: Hogrefe.

LeShan, L.L.. 1952. Time orientation and social class. Journal of Abnormal and Social Psychology $47,589-592$.

Lessing. E.E., 1968. Demographic. developmental, and personality correlates of length of future time perspective (FTP). Journal of Personality 36, 183-201.

Lessing, E.E., 1972. Extension of personal future time perspective, age, and life satisfaction of children and adolescents. Developmental Psychology 6, 457-468.

Lewin, K., 1948. 'Time perspective and morale'. In: K. Lewin (ed.), Resolving social conflicts. New York: Harper. pp. 103 124.

Lewin, K., 1965. 'Group decision and social change'. In: H. Proshansky and B. Seideriberg (eds.). Basic studies in social psychology. New York: Holt. pp. 423-437.

Lösel, F., 1975. Handlungskontrolle und Jugenddelinquenz. Stuttgart: Enke.

MacDonald, A.P., 1971. Internal-external locus of control: parental antecedents. Journal of Consulting and Clinical Psychology 37, $141-147$.

Mischel, W., 1974. 'Processes in delay of gratification'. In: W. Mischel and L. Berkowitz (eds.). Advances in experimental social psychology 7. New York: Academic Press. pp. 249-292.

Mischel, W.. 1981. 'Objective and subjective rules for delay of gratification'. In: G. d'Ydewalle and W. Lens (cds.), Cognition in human motivation and learning. Hillsdale, NJ: Erlbaum; Louvain: University Press.

Nuttin, J., 1964. The future titne perspective in human motivation and learning. Proceedings of the 17th International Congress of Psychology. Amsterdam: North-Holland.

Nuttin, J. and R. Grommen, 1975. 'Zukunftsperspektive bei Erwachsenen und älteren Menschen bei drei sozioökonomischen Gruppen'. In: U. Lehr and F.E. Weinert (eds.), Entwicklung und Persönlichkeit. Stuttgart: Kohlhammer.

Piaget, J., 1946. Le développement de la notion du temps chez l'enfant. Paris: Presses Universitaires de France.

Piaget, J., 1966. 'Time perception in children'. In: J.'T'. Fraser (ed.), The voices of time. New York: Braziller.

Piaget, J., 1970. Genetic epistemology. New York: Columbia University Press. 
Platt, J.J. and R. Eisenman, 1968. Internal-external control of reinforcement, time persepctive, adjustment, and anxiety. Journal of General Psychology 79, 121-128.

Platt, J.J. and R.E. Taylor, 1966. Homesickness, future time perspective, and the self concept. Proceedings of the 74th Meeting of the American Psychological Association 1. 295-296.

Platt, J.J., R. Eisenman, O. DeLisser and A. Darbes, 1971. Temporal perspective as a personality dimension in college students: a re-evaluation. Perceptual and Motor Skills 33, $103-109$.

Raynor, J.O., 1969. Future orientation and motivation of immediate activity: an elaboration of the theory of achievement motivation. Psychological Revicw 76, 606-610.

Raynor, J.O., 1970. Relationships between achievement-related motives, future orientation, and academic performance. Journal of Personality and Social Psychology 15, 28-33.

Raynor, J.O., 1974. 'Future orientation in the study of achievement motivation'. ln: J.W. Atkinson and J.O. Raynor (eds.), Motivation and achievement. Washington. D.C.: Winston.

Raynor, J.O. and E.E. Entin, 1982. Motivation, career striving, and aging. Washington/New York/London: Hemisphere.

Rheinberg, F., 1980. Leistungsbewertung und Lernmotivation. Göttingen: Hogrefe.

Rosenthal, R., 1974. On the psychology of the self-fulfilling prophecy: further evidence for Pygmalion effects and their mediating mechanisms. New York: MSS Modular Publications.

Rotter, J.B., 1966. Generalized expectancies for internal versus external control of reinforcement. Psychological Monograph 80, no. 609.

Ruiz, R.A., R.S. Reivich and H.H. Krauss, 1967. Tests of temporal perspective: do they measure the same construct? Psychological Reports 21, 849-852.

Schnidt, R.W., H. Lamm and G. Trommsdorff, 1978. Social class and sex as determinants of future orientation (time perspective) in adults. European Journal of Social Psychology 8, $71-90$.

Shannon, L., 1975. Development of time perspective in three cultural groups: a cultural difference or an expectancy interpretation. Developmental Psychology 11, 114-115.

Spivack, G. and M. Levine, 1963. Self-regulation in acting out and normal adolescents. Devon, PA: Devereux Foundation.

Stapf, U.H., T. Herrmann, A. Stapf and K. Stäcker, 1972. Psychologic des elterlichen Erziehungsstils. Bern/Stuttgart: Huber.

Stein, K.B., T. Sarbin and J.A. Kulik, 1968. Future time perspective: its relation to the sociali ation process and the delinquent role. Journal of Consulting and Clinical Psychology 32, 257-264.

Teahan. J.E., 1958. Future time perspective, optimism, and academic achievement. Journal of Abnormal and Social Psychology 57, 379-380.

Trommsdorff, G., 1982. 'Group influence on judgments concerning the future'. In: M. Irle (ed.), Studies in decision making. Berlin/New York: de Gruyter.

Trommsdorff, G. and H. Lamm, 1975. 'An analysis of future orientation and some of its social determinants'. In: J.T'. Fraser and N. Lawrence (eds.). The study of time. Heidelberg/New York: Springer. pp. 343-361.

Trommsdorff, G. and H. Lamm, 1976. Fragebogen zur Erfassung von Zukunftsorientierung. Unpublished manuscript, Sonderforschungsbereich 24, Universität Mannheim.

Trommsdorf, G. and H. Lamm, 1980. Future orientation of institutionalized and noninstitutionalized delinquents and nondelinquents. European Journal of Social Psychology 10, 247--278.

Trommsdorff, T., C. Burger and T. Füchsle, 1978a. Zeitperspektive in ihrer Bedeutung für Entscheidung und Handeln. Finanzierungsantrag 1979--1981, SFB 24, Universität Mannheim.

Trommsdorff, T., C. Burger and T. Füchsle, 1980. Geschlechtsdifferenzen in der Zukunftsorientierung. Zeitschrift für Soziologie 9, 366-377.

Trommsdorff, G., C. Burger and T. Füchsle, 1982. 'Social and psychological aspects of future orientation'. In: M. Irle (ed.), Studies in decision making. Berlin/New York: de Gruyter. 
Trommsdorff, G., C. Haag and R. List, 1979a. Zukunftsorientierung, Belobnungsaufschub und Risikobereitschaft bei weiblichen jugendlichen Delinquenten. Kölner Zeitschrift für Soriologie und Sozialpsychologie 31, 732-745.

Trommsdorff, G., H. Iamm and R.W. Schmidt, 1979b. A longitudinal study of adolescents' future orientation (time perspective). Journal of Youth and Adolescence 8, 131- 147.

Trommsdorff, G., C. Burger, T. Füchsle and H. Lamm, 1978b. Erziehung für die Zukunft. Düsseldorf: Schwann.

Trudewind, C. and W. Kohne, 1982. 'Bezugsnorm-Orientierung der Lehrer und Motiventwickhing: Zusammenhänge mit Schulleistung, Intelligenz und Merkmalen der häuslichen Umwelt in der Grundschulzeit'. In: F. Rheinberg (ed.), Bezugsnormen zur Schulleistungsbewertung: Analyse und Intervention. Düsseldorf: Schwann.

Vroom. V.H., 1964. Work and motivation. New York: Wiley.

Wallace, M., 1956. Future time perspective in schizophrenia. Journal of Abnormal and Social Psychology 52, 240-245.

Winnubst. J.A.M., 1975. Het Westerse tijdsyndroom. Conseptuele integratie en eerste aanzet tot construct validatie van een reeks molaire tijdsvariabelen in de psychologie. Amsterdam: Swets \& Zeitlinger.

Wohlford, P. and J.A. Herrera, 1970. TAT stimulus-cues and extension of personal time. Journa! of Projective Techniques and Personality Assessment 34, 31-37.

Zurcher, L.A. Jr., J.E. Willis, F.F. Ikard and J.A. Dohme, 1967. Dogmatism, future orientation, and perception of time. Journal of Social Psychology 73, 205-209.

La présente étude traite de la question de savoir quelles sont les relations existants entre l'orientation future et la socialisation. Tout d'abord, il y a lieu de discuter de la nature de l'orientation future et, par conséquent, d'étudier les variab!es de personnes qui y sont affércntes. II est prouvé qu'une théorie fonctionnelle de la personnalité et du comportement social est nécessaite pour spécifier les relations entre ces variables. C'cst sur base d'une telle théorie qu'on peut traiter d'une façon plus fructueuse de la question de l'ćvolution de l'orientation future. Parallelement au processus de maturité cognitive, les expériences sociales déterminent le sens dans lequel l'orientation future évoluera et agira dans des situations sociales diverses. Enfin sera traitée la question de savoir dans quelle mesure l'orientation future (donnée non seulement par les professeurs et les parents, mais aussi par les personnes socialisées) influe sur le processus de socialisation et sur son résultat. Quelques résultats provisoires signalent l'utilité d'une théorie de l'interaction pour l'étude des relations entre l'orientation future et la socialisation. 